\title{
Keterawetan Kayu Anggerung
}

\author{
Taman Alex* \\ Prodi Rekayasa Kayu, Politeknik Pertanian Negeri \\ Samarinda, Samarinda, 75131 \\ tamanalex2@gmail.com \\ *Corresponding author
}

\author{
Budi Winarni \\ Prodi Pengelolaan Perkebunan, Politeknik Pertanian \\ Negeri Samarinda, Samarinda, 75131 \\ bwinarni14@gmail.com
}

\begin{abstract}
Abstrak - Kayu anggerung (Trema orientalis) saat ini belum banyak dimanfaatkan sebagai bahan konstruksi, karena mempunyai sifat keawetan atau daya tahan rendah terhadap perusak kayu secara alami. Tujuan penelitian ini adalah untuk mengetahui nilai keterawetan kayu anggerung. Penelitian ini didasarkan pada nilai retensi aktual dan nilai porositas kayu dengan cara mencari nilai tinggi resapan air terkoreksi (Corrected Water Absorption Height). Untuk uji berat jenis dan kadar air kayu anggerung dibuat contoh uji berukuran $2 \times 2 \times 2 \mathrm{~cm}$. Untuk mencari nilai retensi pada konsentrasi tembaga sulfat $2 \%$, $3 \%$ dan $4 \%$ menggunakan contoh uji berukuran $2 \times 2 \times 20$ $\mathrm{cm}$. Pengukuran porositas pada air dengan cara membuat serbuk kayu anggerung dikeringkan dengan oven. Hasil penelitian menunjukkan bahwa nilai retensi aktual tertinggi berdasarkan rendaman selama 2 minggu terdapat pada konsentrasi tembaga sulfat $4 \%$, dan nilai porositas menunjukkan bahwa kayu anggerung termasuk jenis kayu yang mudah diresapi bahan pengawet.
\end{abstract}

Kata Kunci-Keterawetan, tembaga sulfat, kayu anggrung.

\section{PENDAHULUAN}

Kayu merupakan salah satu bahan yang penting bagi kehidupan manusia untuk berbagai keperluan seperti untuk bahan energi, konstruksi dan industri lainnya. Pilihan kayu sebagai bahan konstruksi menghendaki pengetahuan sifat-sifat dari kayu tersebut agar dalam penggunaannya dapat dioptimalkan baik dari segi teknis maupun ekonomis (Yoresta, 2015). Salah satu kegunaan kayu adalah sebagai bahan konstruksi bangunan perumahan dan gedung. Untuk kegunaan kayu bangunan diperlukan kayu yang memiliki sifat mekanik atau sifat kekuatan dan sifat keawetan tinggi (Diredja dan Suryoatmono, 2016). Sifat kekuatan dan sifat keawetan digolongkan ke dalam kelas kuat dan kelas awet. Kayu yang berasal dari hutan alam dengan kelas kuat dan kelas awet tinggi mulai langka, sedangkan jenis-jenis kayu komersil seperti kapur dan meranti ketersediaannya sudah sangat berkurang, karena terjadinya degradasi hutan alam.

Penggunaan jenis-jenis kayu kualitas rendah untuk keperluan perumahan telah mendorong usaha peningkatan mutu kayunya melalui pengawetan dengan menggunakan bahan pengawet yang bertujuan untuk meningkatkan keawetan kayu dan sekaligus meningkatkan kekuatannya (Diba et al, 2011). Mayoritas kayu di Indonesia memiliki sifat kekuatan dan keawetan alami yang rendah, hal ini karena kayu pada umumnya memiliki kerapatan rendah atau banyak berongga, sehingga diperlukan rekayasa dengan cara pengawetan kayu untuk meningkatkan kualitas keawetan dan kekuatan kayu (Djarwanto et al, 2015).

Kayu anggerung (Trema orientalis) merupakan tumbuhan dari anggota famili Ulmaceae. Kayu anggrung adalah salah satu bahan yang penting bagi kehidupan manusia untuk berbagai keperluan seperti untuk bahan energi, konstruksi dan industri lainnya. Kayu anggerung merupakan tumbuhan pioner pada lahan yang telah terbuka, pertumbuhannya sangat cepat, umur 5 tahun diameter batang dapat mencapai $30 \mathrm{~cm}$. Berdasarkan klasifikasi keawetan dan kekuatan, kayu ini termasuk dalam kelas awet V dan kelas kuat IV-V (Seng, 1990).

Keawetan kayu berhubungan erat dengan cara pemakaiannya. Nilai suatu jenis kayu ditentukan oleh keawetannya secara alami karena bagaimanapun kuatnya kayu tersebut digunakan tidak akan berarti jika keawetannya rendah. Kayu dikatakan awet apabila umur pakainya panjang dan mampu menahan berbagai macam serangan makhluk hidup perusak kayu seperti jamur, serangga dan binatang laut penggerak kayu (Hossain et al, 2013).

Teknologi pengawetan kayu adalah suatu perlakuan untuk merekayasa dan memperbaiki kualitas kayu dengan cara memasukkan bahan kimia ke dalam kayu agar kayu menjadi lebih tahan lama/awet dalam pemakaian dan dapat meningkatkan kekuatan kayu (Muin dan Arif, 2006).

Retensi aktual adalah retensi yang memperhitungkan persentase rongga sel kayu, sehingga bahan pengawet hanya menempati ruang-ruang kosong dalam kayu. Dengan demikian retensi aktual merupakan retensi realistis bahan pengawet yang terdapat di dalam kayu. Nilai retensi aktual menggambarkan besarnya keterawetan kayu. Retensi bahan pengawet kayu adalah jumlah bahan pengawet kayu yang terdapat pada kayu yang telah diawetkan, dikalikan dengan konsentrasi larutan dalam satuan $\mathrm{kg} / \mathrm{m}^{3}$, merupakan indikator keberhasilan pengawetan kayu (Alex et al, 2018). Nilai retensi bahan pengawet larut air yang tinggi sangat diperlukan untuk menjaga kestabilan keberadaan bahan pengawet di dalam kayu (Alex et al, 2017).

Penelitian ini bertujuan untuk mengetahui nilai keterawetan kayu anggerung dengan indikator nilai retensi bahan pengawet tembaga sulfat dan nilai porositas kayu.

\section{METODOLOGI}


Penelitian ini dilaksanakan di Laboratorium Rekayasa Kayu Politeknik Pertanian Negeri Samarinda. Pengambilan kayu anggerung dilakukan di areal Politeknik Pertanian Negeri Samarinda.

Bahan yang digunakan pada penelitian ini adalah kayu anggerung, tembaga sulfat dan air. Alat yang digunakan adalah ember, baskom, timbangan, oven, gelas ukur, bak rendaman, saringan, meteran, kaliper, $\mathrm{pH}$ meter, areometer, moisture meter, gergaji rantai, gergaji belah, gergaji potong, planner, chipper dan pipa kaca.

Prosedur penelitian dimulai dari penebangan kayu anggerung, dilanjutkan dengan pemotongan, pembelahan dan pengetaman kayu untuk mendapatkan contoh uji dengan ukuran $2 \times 2 \times 20 \mathrm{~cm}$ sebanyak 30 buah untuk diawetkan dan contoh uji $2 \times 2 \times 2 \mathrm{~cm}$ untuk uji berat jenis dan kadar air kayu. Contoh uji yang berukuran $2 \times 2 \times 20$ $\mathrm{cm}$ dikeringudarakan selama dua minggu sampai kadar air berkisar $20 \%$ diukur dengan moisture meter, selanjutnya diukur volume dan beratnya.

Pembuatan larutan tembaga sulfat dengan cara serbuk tembaga sulfat dimasukkan ke dalam air dengan konsentrasi 2\%, 3\% dan 4\%. Untuk pembuatan konsentrasi larutan $2 \%$, maka 20 g serbuk tembaga sulfat dimasukkan ke dalam air hingga volume larutan mencapai $1000 \mathrm{ml}$, demikian seterusnya untuk pembuatan konsentrasi larutan lainnya. Pengukuran derajat keasaman larutan dengan $\mathrm{pH}$ meter dan berat jenis larutan dengan areometer.

Perendaman dengan larutan tembaga sulfat selama satu minggu masing-masing contoh uji sebanyak 10 buah untuk setiap konsentrasi, diukur beratnya untuk menghitung nilai retensi yang merupakan salah satu indikator keterawetan kayu.

Pengukuran keterawetan kayu dengan uji porositas kayu menggunakan nilai tinggi resapan air terkoreksi (Corrected Water Absorption Height) atau metode CWAH menurut Sucipto (2009) dengan cara membuat serbuk kayu berukuran 60 mesh, diukur kadar airnya dengan metode gravimetri, yaitu mengukur berat awal serbuk (W1), kemudian serbuk dikeringtanurkan di oven pada suhu $102 \pm 2{ }^{\circ} \mathrm{C}$ selama 24 jam atau sampai beratnya konstan (W2). Tabung kaca sepanjang $50 \mathrm{~cm}$ dengan diameter $0,46 \pm 0,02 \mathrm{~cm}$ ditimbang beratnya. Serbuk kayu dimasukkan ke dalam tabung kaca. Tabung kaca yang sudah terisi serbuk ditimbang beratnya. Bagian ujung tabung disumbat dengan kapas agar serbuk tidak keluar. Bagian tabung yang ada kapasnya direndam dalam air sedalam 0,5 inch. Dicatat tinggi absorbsi air dalam satuan cm pada 0,5 jam, 2 jam, 4 jam, 24 jam, 48 jam, 72 jam dan 96 jam.

Pengolahan data untuk mengetahui keterawetan kayu anggerung didasarkan pada nilai retensi aktual dan CWAH.

\section{A. Retensi Aktual}

Retensi aktual dapat dihitung dengan rumus yang digunakan oleh industri kehutanan di Indonesia (Siau, 1995).

$$
\begin{gathered}
R A=R x P V R, \\
R=\frac{B 1-B 0}{V} x K, \\
P V R=1-B J\left(\frac{1}{1,53}+\frac{K A T J S}{1,115}\right),
\end{gathered}
$$

Keterangan: $\mathrm{RA}=$ retensi aktual, $\mathrm{R}=$ retensi, $\mathrm{B} 1=$ berat kayu setelah diawetkan, B0 = berat kayu sebelum diawetkan, $\mathrm{K}=$ konsentrasi larutan, $\mathrm{V}=$ volume kayu, $\mathrm{PVR}=$ porsi volume rongga, $\mathrm{BJ}=$ berat jenis, $\mathrm{KATJS}=$ kadar air 30\%, 1,53 = BJ dinding sel, 1,115= BJ air terikat.

\section{B. Tinggi Resapan Air Terkoreksi (CWAH)}

Untuk menghitung nilai CWAH menggunakan rumus berikut ini (Siau, 1995)

$$
C W A H=h 1\left(\frac{d^{2} \pi h 2}{4 w s}\right)
$$

Keterangan: $\mathrm{CWAH}=$ Corrected Water Absorption Height $(\mathrm{mm}), \mathrm{h} 1=$ tinggi resapan atau absorpsi air $(\mathrm{mm})$, $\mathrm{d}=$ diameter bagian dalam tabung kaca $(\mathrm{cm}), \mathrm{h} 2=$ tinggi serbuk dalam tabung kaca $(\mathrm{cm}), \mathrm{w}=$ berat kering tanur serbuk $(\mathrm{g}), \mathrm{s}=$ volume jenis air $\left(\mathrm{cm}^{3} / \mathrm{g}\right)$.

\section{HASIL DAN PEMBAHASAN}

\section{A. Retensi Aktual}

Besarnya nilai retensi aktual disajikan pada Tabel 1.

Tabel 1. Nilai Retensi Aktual $\left(\mathrm{kg} / \mathrm{m}^{3}\right)$

\begin{tabular}{|c|c|c|c|}
\hline \multirow{2}{*}{$\begin{array}{c}\text { Waktu } \\
\text { rendaman } \\
\text { (minggu) }\end{array}$} & \multicolumn{3}{|c|}{ Konsentrasi larutan (\%) } \\
\cline { 2 - 4 } & 2 & 3 & 4 \\
\hline 1 & 3,15 & 3,08 & 3,62 \\
\hline 2 & 5,69 & 5,70 & 8,31 \\
\hline
\end{tabular}

Kayu anggerung memiliki berat jenis kayu yang rendah sekitar 0,4-0,5. Barly dan Lelana (2010) menyatakan bahwa retensi bahan pengawet dipengaruhi oleh kerapatan atau berat jenis kayu. Semakin tinggi berat jenis, semakin sulit kayu diresapi bahan pengawet. Semakin rendah berat jenis kayu akan semakin besar kandungan rongga sel kayu. Proporsi jaringan sel berkorelasi dengan besarnya pembuluh, jumlah dan besarnya pembuluh akan berpengaruh pada kandungan bahan pengawet di dalam kayu. Jumlah dan ukuran besarnya pembuluh sangat berkaitan dengan kerapatan atau berat jenis kayu (Wen et al, 2014). Kayu anggerung yang diawetkan dengan nanopartikel liat dari hasil pengamatan dengan Scan Electron Microscopy (SEM) menunjukkan bahwa nanopartikel liat hanya menempel pada lubang pori. Hal ini menggambarkan bahwa kayu anggerung secara alami mempunyai lubang pori yang kosong (Alex et al, 2018). 
Menurut Martawijaya dan Barly (2010) retensi bahan pengawet tembaga sulfat minimal $8 \mathrm{~kg} / \mathrm{cm}^{3}$. Bahan pengawet larut air dapat menyebar secara merata dan mudah meresap ke dalam kayu, tetapi mudah larut atau terdegradasi (Febrianto et al, 2014). Berdasarkan nilai retensi aktual pada Tabel 1 menunjukkan bahwa retensi bahan pengawet larutan tembaga sulfat konsentrasi $4 \%$ yang direndam dengan selama dua minggu nilainya lebih besar dari $8 \mathrm{~kg} / \mathrm{m}^{3}$.

\section{B. Tinggi Resapan Air Terkoreksi (CWAH)}

Hasil perhitungan nilai CWAH berdasarkan waktu disajikan pada Tabel 2.

Tabel 2. Nilai CWAH Berdasarkan Waktu

\begin{tabular}{|c|c|c|}
\hline Periode & Waktu (jam) & Nilai CWAH (mm) \\
\hline 1 & 0,5 & 15 \\
\hline 2 & 2 & 24 \\
\hline 3 & 4 & 29 \\
\hline 4 & 24 & 42 \\
\hline 5 & 48 & 57 \\
\hline 6 & 72 & 62 \\
\hline 7 & 96 & 62 \\
\hline
\end{tabular}

Besarnya nilai CWAH memberikan informasi mengenai mudah tidaknya kayu diresapi larutan bahan pengawet. Nilai CWAH besar berarti kayu mempunyai porositas tinggi, artinya kayu mudah menyerap larutan bahan pengawet. maka kayu akan mudah diawetkan. Nilai CWAH berhubungan dengan penyerapan larutan oleh rongga sel. Kayu semakin padat atau dinding sel kayu semakin tebal, maka porositas kayu semakin rendah, yang berarti semakin sulit diresapi laarutan pengawet kayu. Demikian pula sebaliknya apabila dinding sel kayu semakin tipis, maka porositasnya semakin besar, semakin mudah diresapi larutan pengawet kayu. Menurut Sucipto (2009) kayu berkerapatn rendah (porositas tinggi) menjadi lebih baik untuk dibasahi, sedangkan ekstraktif dalam jumlah berlebihan atau ekstraktif nonpolar, seperti terpena dan asam lemak mempunyai pengaruh kurang baik. Berkurangnya zat ekstraktif menyebabkan naiknya nilai absorbsi air yang berarti menaikkan nilai keterbasahan (CWAH).

Pada Tabel 2 menunjukkan bahwa pada periode ke-1 (0,5 jam atau 30 menit pertama) mendapatkan nilai CWAH 15. Pada periode ke-6 (72 jam), didapat nilai CWAH 62. Nilai tersebut pada periode ke-7 (96 jam) tetap diangka 62, berarti setelah 72 jam (3 hari) tidak terjadi penyerapan larutan bahan pengawet lagi. Kecepatan penyerapan air dari periode 1 (0,5 jam) sampai periode 5 (48 jam $=2$ hari) menunjukkan kenaikan tajam, selanjutnya mulai mendatar dan berhenti pada periode ke6 (72 jam $=3$ hari). Pengamatan terus dilakukan hingga periode ke-7 (96 jam $=4$ hari) dan tidak mengalami kenaikan nilai CWAH.

\section{KESIMPULAN}

Keterawetan kayu anggrung berdasarkan hasil uji retensi aktual dengan proses rendaman dengan bahan pengawet tembaga sulfat dan uji porositas dengan metode CWAH, dapat disimpulkan bahwa kayu anggerung adalah jenis kayu yang mudah diawetkan. Dari hasil penelitian ini menunjukkan bahwa kayu anggerung secara alami memiliki keawetan yang rendah, sehingga diperlukan rekayasa pengawetan untuk dapat dimanfaatkan sebagai kayu konstruksi.

\section{DAFTAR PUSTAKA}

Alex, T., Winarni, B., Kusuma, I. W., Arung, E. T., \& Budiarso, E. (2017). The clay nanoparticles impregnation for increasing the strength and quality of sengon (paraserienthes falcataria) and white meranti (shorea bracteolate) timber. Journal Nusantara Bioscience, 9(1), 107-110.

https://doi.org/10.13057/nusbiosci/n090119

Alex, T., Winarni, B., Kusuma, I. W., Arung, E. T., \& Budiarso, E. (2018). The efect of clay nanoparticle on the retention and attack of drywood termite (cryptotermes cynocephalus light). IOP Conference Series: Earth Environ. Science https://iopscience.iop.org/article/10.1088/17551315/144/1/012062/meta

Barly \& Lelana, N. E. (2010). Pengaruh ketebalan kayu, konsentrasi larutan dan lama perendaman terhadap hasil pengawetan kayu. Jurnal Penelitian Hasil Hutan, 28(1), 1-8.

https://doi.org/10.20886/jphh.2010.28.1.1-8.

Diba, F., Oramahi, O. H., and Wahdina. (2011). Antitemitic activity of wood vinegar and its component. Proceeding The 1 International Wood Research Symposium. p 89-93. Faculty of Forestry Universitas Gadjah Mada, Yogyakarta.

Diredja, N.V., \& Suryoatmono, B. (2016). Studi ekspreimental geser blok pada batang tarik kayu Indonesia. Jurnal Teknik Sipil Maranata, 12(2), 99101. https://doi.org/10.28932/jts.v12i2.1418

Djarwanto, Suprapti, S., \& Hudiansyah. (2015). Pelapukan lima jenis kayu oleh beberapa jamur perusak. Prosiding Seminar Nasional MAPEKI XVII, h 201-205. Pusat Penelitian Biomaterial Lembaga Ilmu Pengetahuan Indonesia, Bogor http://repository.usu.ac.id/bitstream/handle/12345678 9/66560/artikel.pdf.

Febrianto, F., Gumilang, A., Carolina, A., \& Yoresta, F. S. (2014). Distribusi bahan pengawet larut air pada kayu diawetkan secara sel penuh dan sel kosong. Jurnal Ilmu dan Teknologi Kayu Tropis, 12(1), 26-35. http://ejournalmapeki.org/index.php/JITKT/article/ view/79.

Hossain, A., Rahman, A. N. M. M., Hasan, M. M., Karmakar, S., \& Zaman, M. A. (2013). Enchancement of wood preservation technology by pressure and nonpressure process and comparison of their properties. Inter J of Sci and Eng Res 4(8): 992-1005. https://doi.org/10.14299/ijser.2013.08.002

Martawijaya, A., \& Barly. (2010). Pedoman Pengawetan Kayu. IPB Press. 
Muin, M., \& Arif, A. (2006). Keterawetan kayu tropis dengan proses pengawetan menggunakan karbon dioksida sebagai pelarut pembawa. Jurnal Ilmu dan Teknologi Kayu Tropis, 4(2), 66-70.

http://www.ejournalmapeki.org/index.php/JITKT/arti cle/view/280

Seng, O.D. 1990. Berat Jenis dari Jenis-jenis Kayu di Indonesia dan Pengertian Beratnya Kayu untuk Keperluan Praktek. Pengumuman Nr.13 Pusat Penelitian dan Pengembangan Hasil Hutan, Departemen Kehutanan, Bogor.

Sucipto, T. (2009). Determinasi keterbatasan (wettability) kayu. Karya Tulis. Departemen Kehutanan Fakultas Kehutanan Universitas Sumatera Utara.

http://repository.usu.ac.id/bitstream/handle/12345678 9/1035/10E00550.pdf.

Wen, M.Y., Kang, C. W., \& and Park, H. J. (2014). Impregnation and mechanical properties of three softwood treated with a new fire-retardant chemical. Journal Wood Science, 60, 367-375. https://jwoodscience.springeropen.com/articles/10.10 07/s10086-014-1408-0

Yoresta, F.S. (2015). Modulus elastisitas dan kekuatan lentur balok kayu laminasi. Jurnal Rekayasa Sipil, 11(1), 40-43.

https://doi.org/10.25077/jrs.11.1.41-44.2015 